\title{
GEOMATIC TECHNIQUES FOR THE OPTIMIZATION OF SKI RESOURCES
}

\author{
I. Aicardi ${ }^{1,2}$, S. Angeli $^{1}$, N. Grasso ${ }^{1 *}$, A.M. Lingua ${ }^{1,2}$, P. Maschio $^{1}$, \\ ${ }^{1}$ DIATI, Politecnico di Torino, Torino, Italy, 10124 Corso duca degli Abruzzi,24 Torino - $\{$ irene.aicardi, nives.grasso, \\ andrea.lingua, paolo.maschio, stefano.angeli\}@ polito.it \\ ${ }^{2}$ PIC4SeR, Politecnico di Torino Interdepartmental Centre for Service Robotics, Torino, Italy
}

Commission II, WG II/10

KEY WORDS: aerial photogrammetry; unmanned aerial vehicle (UAV); GNSS; ski; snow depth.

\begin{abstract}
:
Climate change is already affecting the entire world, with extreme weather conditions such as drought, heat waves, heavy rain, floods and landslides becoming more frequent, including Europe. In according to Paris agreement and relative European announcement of Carbon neutrality (by 2050), the saving of water and energy supplies is a fundamental aspect in the management of resources in production, sports, hospitality facilities and so on. Some methodologies for the optimization of the consumption of natural resources are required. This article describes an activity aimed at measuring, monitoring and analysing the thickness of the snowpack on the ski slopes during the winter season to permit a sustainable approach of snowmaking in alpine ski areas . The authors propose a methodology based on the integration of multitemporal surface (ground/snow) survey by Autonomous Aerial Vehicle (AAV) and low cost GNSS receivers mounted on snow groomers for a RTK (Real Time Kinematic) solution. To obtain a complete snow surface digital models with poor detailed images on ski slopes, some pre-processing techniques have been analysed to locally improve contrast and details with a local high pass filtering. The methodology has been employed in two study areas (Limone Piemonte, Prato Nevoso) located in the province of Cuneo, in the southern alpine area of Piedmont.
\end{abstract}

\section{INTRODUCTION}

Energy efficiency and the containment of climate-changing gas emissions are a priority also for tourist facilities (Dawson and Scott, 2013). In particular, in the alpine environment, the consumption for heating and the production of domestic hot water represent an important cost item for structures linked to ski tourism, such as hotels, catering establishments, ticket offices, changing rooms and shops. These costs are also due, in many cases, to the absence of methane that forces the structures to resort to more expensive solutions, such as diesel and GPL.

On the other hand, the production of artificial snow is also becoming a big problem in relation to climate change. This is because it is increasingly difficult to produce it (due to the increase in temperatures) and its production takes on high costs (Scott et al., 2019). In recent years, ski resorts have increasingly had to exploit the production of artificial snow, mainly to limit the effects that the variability of snow conditions may have on the activities of ski resorts; However, artificial snowmaking can be considered a form of adaptation to climate change (Steiger et al., 2017). Moreover, ski resorts tend to produce artificial snow in less than optimal conditions and this further increases costs, as well as environmental impact. This is, mainly, because often there is no real knowledge and sensitivity with respect to real production costs and consumption and because, often, ski resorts prefer to produce in excess rather than being found unprepared. One of the major energy consumption items of the ski resorts concerns the manufacture of artificial snow, a requirement which is also growing due to climate change and which determines a strong environmental pressure both locally, with the need to create special reservoirs at high altitude or water withdrawals during the winter (which, however, in our latitudes represents the second lean season after the summer), both globally, with strong emissions of climate-changing gases linked to the production of electricity that feeds the cannons for snow production (Rixen et al., 2011).

As part of the PITER Alpimed - Innov Project funded by the European INTERREG programme Alcotra, the Living Lab on ski resorts (action 4.1.3 of the project - 2018/2021) provides for the study and testing of initiatives to reduce energy and water consumption linked to ski Slopes. Politecnico di Torino is testing different technical solutions to support ski resorts in the search for maximum energy efficiency. Alpimed - Innov is an ambitious cooperation project to promote innovative strategies in the Mediterranean Alps. It is a cross-border territory that has great potential, but that shares the same basic problems: the economy of these territories is mainly oriented to tourism, but it struggles to keep up with innovative processes and the urgent need to reorient resource exploitation policies in an eco-sustainable way. The objective of the Alpimed - Innov Project is to provide an integrated response to the needs of these territories by facilitating access to innovation and the dissemination of new technologies, implementing actions and strategies to address some of the main challenges related to climate change and finally encouraging the promotion of the territory. The first season was dedicated to the collection of data on some ski resorts, with regard to the energy consumption of the facilities, the water and energy consumption of artificial snow and their management practices.

There are several possible technical-scientific aspects of the proposed monitoring:

1) Measurement of power consumption profiles provides an indication of the "carbon footprint" of the artificial snowmaking; 2) measurement of the water flows required to quantify the water requirement of artificial snow and, therefore, to enrich the statistical basis for the design of future dedicated reservoirs;

\footnotetext{
* Corresponding author
} 
3) measurement of water consumption related to that of climate parameters (temperature, relative humidity);

4) measurement of the height of snow from the ground, carried out with drone and GNSS RTK measurements, which will allow you to understand the potential (detection speed, accuracy, etc. ) different types of sensors for this purpose and will define their feasibility and possible adoption by individual operators;

5) survey of the routes of the snow groomer vehicles, which will allow to quantify the fuel consumption attributable to the typing of each track during the year and, through their analysis, the optimization of the typing layout, to provide technical managers with information to rationalize their routes and, if necessary, to remodel some sections of the track so as to consume less fuel.

In this context, recent developments in geomatics technologies, in particular UAVs (Unmanned Aerial Vehicles) and GNSS (Global Navigation Satellite Systems) receivers, offer interesting opportunities for the optimization of artificial snow production. With the emergence of consolidated technologies in the field of measurement and monitoring, classic manual measurement techniques, directly on site, are increasingly being replaced by new methods that involve the use of SAR and Optical Remote Sensing data, Terrestrial Laser Scanner (TLS), Ground Penetrating Radar (GPR), Tachymetry and photogrammetry techniques from UAV (Unmanned Aerial Vehicle) or terrestrial, thanks also to the small size of the sensors that allow to implement them in different devices in the mass market (Avanzi et al., 2018; Aicardi et al., 2016b; Masiero et al., 2016; Balletti et al., 2014).

Photogrammetry and structure from motion (SFM) algorithms are becoming more and more used techniques in the analysis, with a certain accuracy, of the depth of the snowpack in alpine environments. Compared to the other techniques mentioned, UAV photogrammetry allows to achieve good accuracy and high detail (Marino et al., 2019) in addition to the removal hidden areas during the survey phase, which mainly characterize terrestrial survey techniques (ex. TLS) in the presence of areas inaccessible from the ground. In addition, this technique is particularly efficient, flexible and repeatable for cost and timesaving monitoring for various applications (Bühler et al., 2016). Obviously, the use of unmanned aerial vehicles also requires various arrangements based on weather conditions, such as the presence of strong wind, based on the presence of people or not in the study area and conditions of the snowpack, characterized by a particularly uniform surface with no easily recognizable details.

Usually the measurement of the depth of the snowpack is carried out with the use of snow depth maps which are calculated through the difference of two elevation models (DEMs) made for the same study area, one relating to acquisitions on the ground without the presence of snow and one on the snowpack (Goetz et al., 2019).

With regard to tracking of snow groomers with GNSS receivers, ski resort managers are strongly interested in acquiring this data to monitor the routes and improve the modelling layout of the slopes in order to reduce fuel consumption. To date, most manufacturers of snow cats are able to install sensors that allow them to trace the path of the vehicles as well as estimate, in real time, the height of the snow cover. However, access to data is only possible through very expensive subscriptions which, especially smaller resorts, would not be able to cover. Currently many types of GNSS receivers are available in the market ranging from geodetic triple frequency and multi constellation to low-cost mass-market single frequency and single constellation receivers. Low-cost and dual frequency receivers can utilize both frequencies (L1 and L2) to remove errors due to atmospheric (e.g. ionosphere) and environmental (e.g. multipath) conditions and an accuracy up to $\mathrm{cm}$ level can be obtained after correctly resolving the carrier-phase integer ambiguities (He et al., 2014). The small dimension of GNSS antennas and receivers allow them to be installed on any kind of vehicle, making them a good solution for the tracking of snow groomers.

This work aims at describing the activities and tests carried out in order to meet the objectives of the project, concerning the estimation of snow depth and monitoring of snow cat paths. In particular, the paper will analyse the results obtained by the reconstruction of a high precision Digital Terrain Model (DTM) of the alpine ski slopes and the realization of experimental measurements of the snow depth from UAVs, in different ski resorts, open to the public during surveys operations.

Moreover, analysis on the use of low-cost receivers for the tracking of the paths of the beating machines will be carried out, for their possible optimization in the following season.

\section{CASE STUDY}

Two case studies have been identified within the project area, among the largest ski areas in the Province of Cuneo (Figure 1). The main idea of the project is that this first data collection will facilitate the exchange of good practices between operators of different stations, from large operators to smaller resorts and presumably with less management skills.

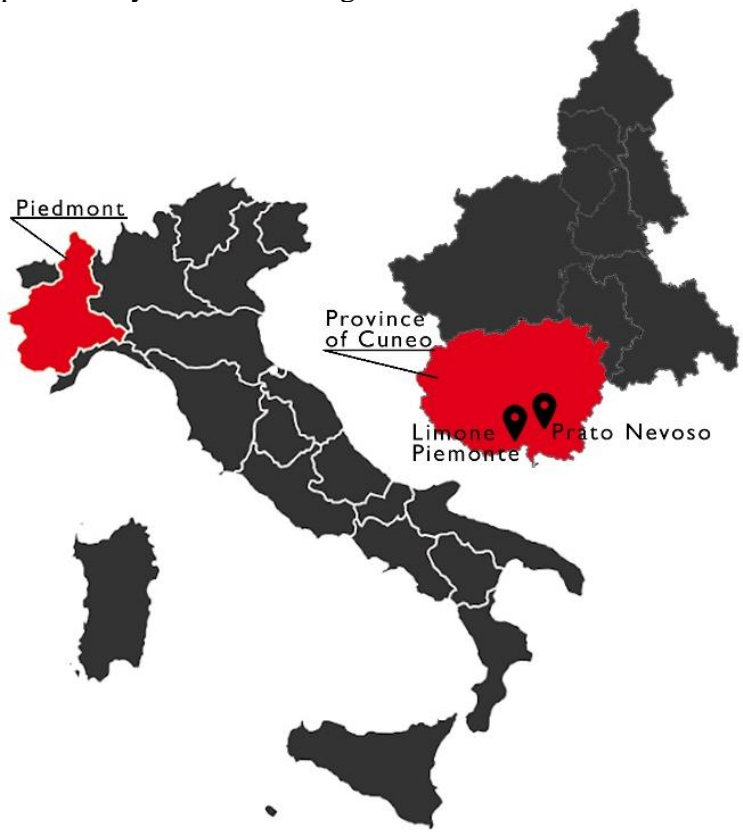

Figure 1. Province of Cuneo, Italy.

The first one is a black track, called Armand slope (ALP), relating to the Limone Piemonte area, which has the following characteristics: minimum altitude $1396 \mathrm{~m}$, maximum altitude $1582 \mathrm{~m}$, mean slope $33 \%$, exposure E. The track is crossed in part by a chair lift and is almost entirely bordered by rather high vegetation. The snowmaking on the Armand track takes place by means of 5 fans that work for about 80-100 consecutive hours with the entire pumping station. Once the working hours have been completed, they are removed and artificial snow is generally used once per season. Each machine is served by a cockpit located along the track. An approximate value of the consumption only to snow the Armand track in the 2018-2019 season was about $5000 \mathrm{~m}^{3}$ that allowed to maintain a snow thickness of about $40 \mathrm{~cm}$ along the entire track, Because with 
lower thicknesses the installation of the posts of the doors would bring to the surface the earth under the snowy mantle (Figure 2).

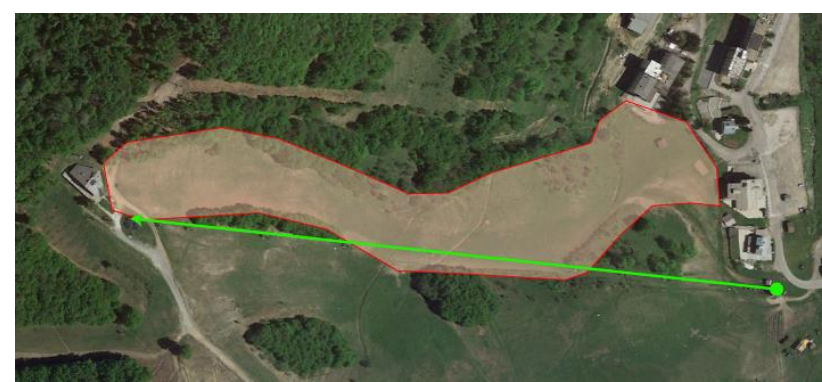

Figure 2. Study area in Limone Piemonte $(\mathrm{CN})$.

The second case study is a blue slope, Prél (PPN), relative to Prato Nevoso which has the following characteristics: minimum altitude $1456 \mathrm{~m}$, maximum altitude $1678 \mathrm{~m}$, mean slope $17 \%$, exposure S-E. On one side of the track there are water basins, some buildings and a treadmill for beginners; while on the other side it is bordered by a hill and, at the bottom, by the snow park. The production of artificial snow in the area of Prato Nevoso takes place through the storage of water in two artificial lakes, upstream of the track, at an altitude of $1978 \mathrm{~m}$. These basins are filled by taking advantage of the overflow of the aqueduct, Capable of providing flow rates up to $25 \mathrm{l} / \mathrm{s}(90 \mathrm{~m} 3 / \mathrm{h})$. The snowmaking takes place through fans and rods, and in winter 2018/2019 were used $140963.2 \mathrm{~m}^{3}$ of water. Here, the minimum required snow thickness is $20 \mathrm{~cm}$ (Figure 3 ).

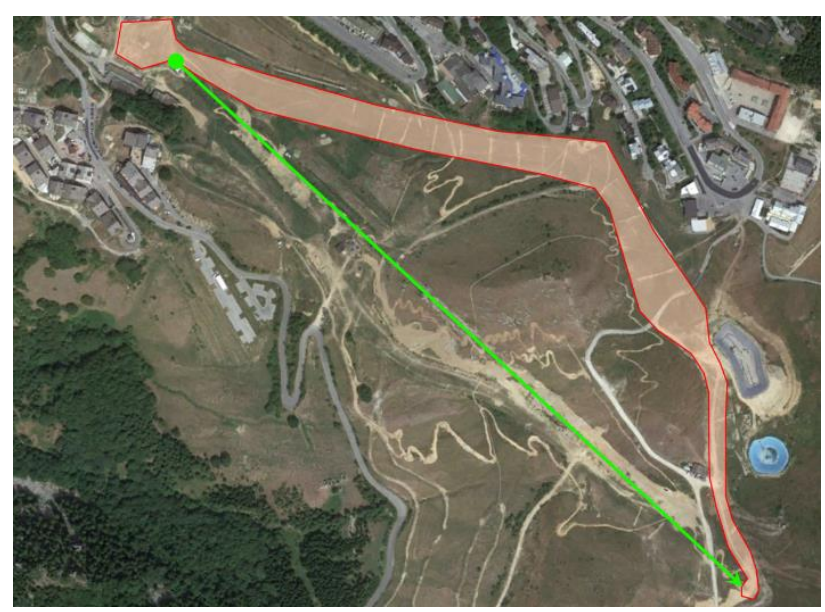

Figure 3. Study area in Prato Nevoso (CN).

\section{THE ACQUISITION METHODOLOGY}

\subsection{Photogrammetric acquisition from UAV}

Acquiring data on ski slopes can be a quite critical operation. This is due not only to the characteristics of the environment, such as the slope of the ground, the presence of vegetation, but also to the presence of anthropic elements, such as buildings on the edge of the track and ski lifts. An aspect that further complicates the acquisition during the winter period is the massive presence of skiers, both on the track and in the surrounding areas. Account should also be taken of how low temperatures affect battery life. In order to perform the tests, it was therefore chosen to exploit different commercial solutions, depending on the context (vegetation, take-off and landing space), working (presence of people on the track) and weather conditions (presence of wind).
Table 1 shows the UAV chosen to collect data and their characteristics.

\begin{tabular}{|l|c|c|c|}
\hline & $\begin{array}{c}\text { DJI Phantom } \\
\text { 4 Pro }\end{array}$ & $\begin{array}{c}\text { DJI Mavic } \\
2 \text { Pro }\end{array}$ & $\begin{array}{c}\text { DJI Mavic } \\
\text { Mini }\end{array}$ \\
\hline Take-off weight & $1388 \mathrm{~g}$ & $907 \mathrm{~g}$ & $249 \mathrm{~g}$ \\
\hline Flight autonomy & $30 \mathrm{~min}$ & $31 \mathrm{~min}$ & $30 \mathrm{~min}$ \\
\hline Flight distance & $14 \mathrm{Km}$ & $18 \mathrm{Km}$ & $16 \mathrm{Km}$ \\
\hline Sensor & 1 CMOS & 1 CMOS & $1 / 2.3 ”$ \\
& $20 \mathrm{MP}$ & $20 \mathrm{MP}$ & $\mathrm{CMOS}$ \\
& & & $12 \mathrm{MP}$ \\
\hline Camera focal & $24 \mathrm{~mm} \mathrm{f} / 2.8-$ & $28 \mathrm{~mm}$ & $24 \mathrm{~mm}$ \\
length & 11 & $\mathrm{f} / 2.8-11$ & $\mathrm{f} / 2.8$ \\
\hline
\end{tabular}

Table 1. Specifications of the used UAV platforms.

For each ski slope three aerial surveys were performed: one to measure the "zero" reference altitude of the ground in the absence of snow, during the summer/autumn season. Two flights were performed during the ski season in order to measure the depth of the snow and validate the procedure.

In order to cover the entire study area, always maintaining a good visibility of the drone, the slopes have been divided into several parts with a maximum height difference of $60 \mathrm{~m}$. In order to strengthen the photogrammetric block, given the inclination of the ground, for each flight, data were acquired from both nadir strips and oblique strips, with a camera inclination of about 30 degrees, corresponding approximately to that of the slope (Aicardi et al., 2016a; Lingua et al., 2017).

According to the UAV platform used and on the onboard camera, flights were performed at such a height to ensure an average Ground Sample Distance (GSD) of approximately $2 \mathrm{~cm}$. In Table 2 the main characteristics of the flights carried out are described.

\begin{tabular}{|l|c|c|c|c|}
\hline \multicolumn{1}{|c|}{ Area } & $\begin{array}{c}\text { People } \\
\text { on the } \\
\text { track }\end{array}$ & UAV & $\begin{array}{c}\text { N. } \\
\text { images }\end{array}$ & $\begin{array}{c}\text { Avg. GSD } \\
{[\mathrm{cm} / \mathrm{px}]}\end{array}$ \\
\hline $\begin{array}{l}\text { ALP No snow } \\
\text { No }\end{array}$ & $\begin{array}{c}\text { Phantom 4 } \\
\text { Pro }\end{array}$ & 1906 & 1.51 \\
\hline $\begin{array}{l}\text { ALP snow } \\
- \text { I test }\end{array}$ & No & $\begin{array}{c}\text { Phantom } 4 \\
\text { Pro }\end{array}$ & 741 & 1.81 \\
\hline $\begin{array}{l}\text { ALP snow } \\
- \text { II test }\end{array}$ & Yes & $\begin{array}{c}\text { Mavic } \\
\text { Mini }\end{array}$ & 937 & 2.02 \\
\hline $\begin{array}{l}\text { PPN NN } \\
\text { No snow }\end{array}$ & $\begin{array}{c}\text { Mavic } 2 \\
\text { Pro }\end{array}$ & 1096 & 1.41 \\
\hline $\begin{array}{l}\text { PPN snow } \\
- \text { I test }\end{array}$ & Yes & $\begin{array}{c}\text { Mavic } \\
\text { Mini }\end{array}$ & 553 & 1.92 \\
\hline $\begin{array}{l}\text { PPN snow } \\
- \text { II test }\end{array}$ & Yes & $\begin{array}{c}\text { Mavic } \\
\text { Mini }\end{array}$ & 721 & 2.43 \\
\hline
\end{tabular}

Table 2. Characteristics of the performed flights.

\subsubsection{Data georeferencing}

Both Ground Control Points (GCPs) and Check Points (CPs) were used to optimise the construction of the photogrammetric block, geo-referencing the model and validating the accuracy of the final result. Before the flights, plasticized markers (40x40 $\mathrm{cm}$ ) were distributed over the study area. Given the need to ensure the safety of skiers, not being able to close the ski slope to the public during the winter, if not for a few minutes, the markers were placed only on the outer sides of the track, on non-beaten snow, and fixed with special nails. The position of the markers was acquired with an GNSS receiver, using an RTK approach (using a GSM Internet connection for receiving corrections) (Figure 4). The coordinates of these points were estimated with centimetric $(3 \mathrm{~cm})$ accuracy and ambiguity set for all points. 


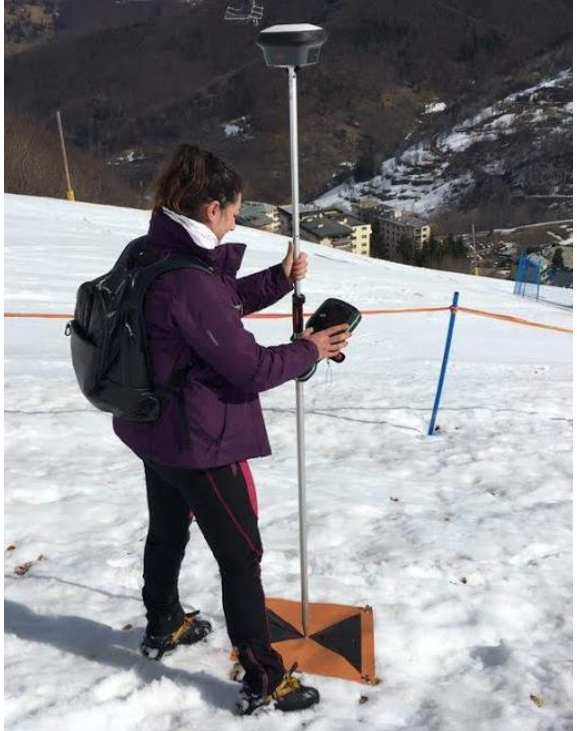

Figure 4. GCPs measurement with RTK approach.

In addition, in Limone Piemonte, a topographical network was created, materializing two vertices and measuring them with a geodetic GNSS receiver in static mode. The coordinates of the points were estimated using data from the permanent station of Mondovì, the CORS (Continously Operation Reference Stations) network of the Piedmont Region, and obtaining a level of millimeter accuracy. Subsequently, some target points that were clearly visible from UAV flights were measured with a total station positioned on the reference vertices (Figure 5).

Measurements were subsequently compensated to estimate the final coordinates with an estimated RMSE lower than one centimeter.

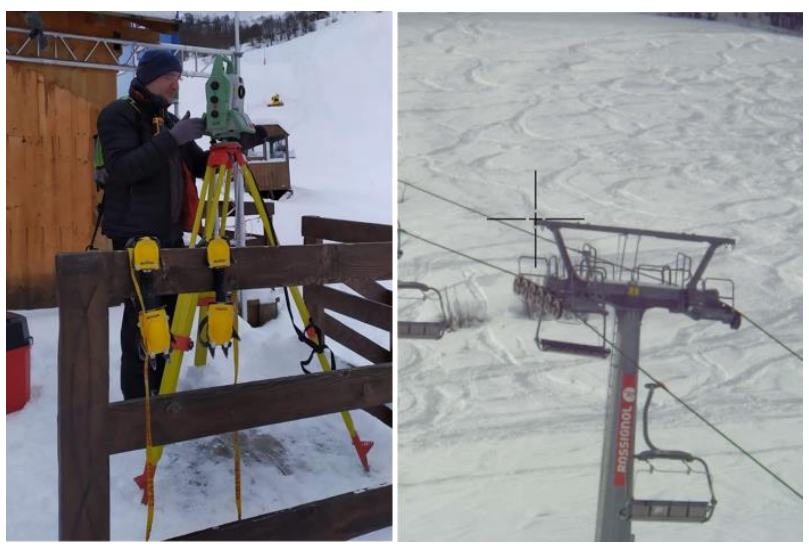

Figure 5. Detail survey with the total station.

On the contrary, on the borders of the Prél track, in Prato Nevoso, there were no natural targets that were visible as drones and useful for the generation of the photogrammetric model.

\subsection{Snow groom tracking}

A further goal of this research was to carry out a test in order to track the snow-beating path carried out by the snow cat and allow the managers of the Limone Piemonte ski slopes to quantify the fuel consumption. To this purpose, we analysed the performances of the Tersus BX-306 (Table 3), a low-cost and dual frequency GNSS RTK board for $\mathrm{cm}$ level positioning: it provides raw measurements which can be integrated with autopilots and inertial navigation units. . Currently, it supports three constellations (GPS L1/L2, GLONASS G1/G2, and BeiDou $\mathrm{B} 1 / \mathrm{B} 2)$ to improve the continuity and reliability of the RTK.

\begin{tabular}{|l|c|}
\hline GNSS Receiver & Tersus Precis BX-306 \\
\hline Image & $\$ 1,699.00$ \\
\hline Price & $3.5 \mathrm{~W}$ \\
\hline Power Consumption & $23 \mathrm{~g}$ \\
\hline Weight & GPS L1/L2, GLONASS \\
\hline Constellations & $1 \mathrm{H}$, BeiDou B1/B2 \\
\hline Position update rate & Tersus Binary Protocol (TRS) \\
\hline Raw data format & RTCM 2.x/3.x/CMR/CMR+ \\
\hline Corrections type & Table 3. Characteristics of Tersus BX-306.
\end{tabular}

This receiver is able to apply differential corrections broadcasted by a software that manages CORSs network and to collect raw data (carrier-phase, pseudoranges and Doppler measurements) on a laptop.

The Tersus BX-306 was employed together with the AX3702 mini survey antenna, the characteristics of which can be seen in Table 4.

The antenna was set up on the top of the vehicle and a laptop, connected to the receiver through USB interface, was placed inside the snow groomer to initiate and record the GNSS data (Figure 6).

\begin{tabular}{|l|c|}
\hline GNSS Antenna & AX3702 \\
\hline Image & \\
\hline Price & $\$ 160.00$ \\
\hline Gain & $5.5 \mathrm{dBi}$ \\
\hline Weight & $374 \mathrm{~g}$ \\
\hline Constellations & $\begin{array}{c}\text { GPS L1/L2, GLONASS } \\
\text { G1/G2, BeiDou B1/B2 }\end{array}$ \\
\hline
\end{tabular}

Table 4. Characteristics of GNSS Antenna AX3702 from Tersus.

The corrections were obtained via radio from a base station placed on a known point of the reference network for accurate real-time positioning, to solve GNSS carrier phase ambiguities. The receiver was set up in order to give a solution with a sample rate of $1 \mathrm{~Hz}$. In addition, it was necessary to initialize the data acquisition a few minutes before the snow cat started to move, as the Tersus GNSS requires a 60 second time to first fix, which it achieves easily even with the longer baseline.

Known the positions measured by the GNSS receiver, it is possible to estimate the height of the snow compared to the snow groom blade, with which the surface will then be modeled. With a total station, the leverage arm between the GNSS antenna and the central point of the blade, which comes into contact with snow, has been estimated. In order to correctly estimate the height of the snow relative to the position of the vehicle, its attitude during movement must be taken into account; therefore, yaw and pitch attitude of the snow groom were estimated 
considering its position compared to the previously estimated one.

Data acquisition was carried out the night before one of the UAV flights and it lasted for about three hours.

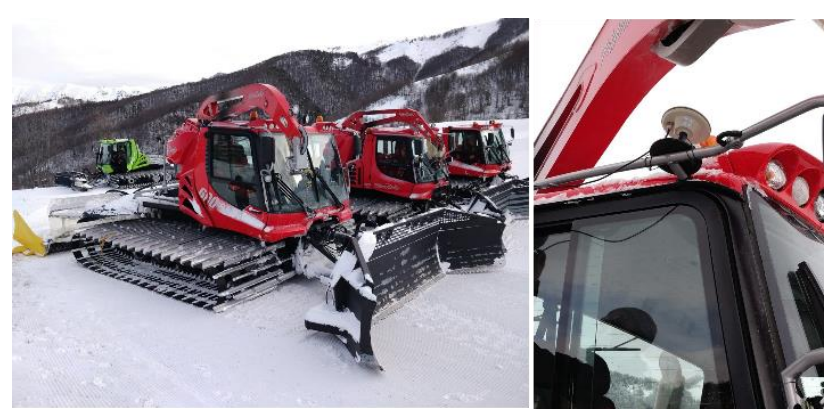

Figure 6. The snow groom (on the left) and the and the installation of the antenna on the top of the vehicle.

\section{PHOTOGRAMMETRIC DATA PROCESSING}

The aim of the aerial image acquisitions was to produce Digital Terrain Models (DTMs) of ski slopes in the presence and not of snow, for the estimation of the snow depth. The six datasets of UAV data were processed using the well-established Structure from Motion (SfM) approach (Turner et al., 2012).

These algorithms, which now are implemented in several commercial software and they all lead to the images alignment, generation of dense point clouds and, subsequently, to the production of a triangulated mesh and to Digital Elevation Models (DEMs) and orthophoto extraction. In this case study, the photogrammetric process has been carried out using the commercial solution AMP (Agisoft Metashape Professional). For each dataset, nadir and oblique images were processed together. The software was set up to align images with "high" accuracy, namely using the images with their original size. To georeference the photogrammetric block and to improve the external orientation estimation, several GCPs have been collimated in the photos, while some CPs have been employed to validate the accuracy of the model (Table 5). 3D dense point clouds have been then produced with a high details level, which means that AMP downscales the original images by a factor of 4 , in order to obtain some products suitable for a large-scale purpose.

\begin{tabular}{|l|c|c|c|}
\hline \multicolumn{1}{|c|}{ Dataset } & $\begin{array}{c}\text { Image Res. } \\
{[\mathrm{px}]}\end{array}$ & N. GCPs & N. CPs \\
\hline $\begin{array}{l}\text { ALP } \\
\text { No snow }\end{array}$ & $5472 \times 3648$ & 41 & 14 \\
\hline $\begin{array}{l}\text { ALP snow } \\
- \text { I test }\end{array}$ & $5472 \times 3648$ & 10 & 5 \\
\hline $\begin{array}{l}\text { ALP snow } \\
- \text { II test }\end{array}$ & $4000 \times 2250$ & 13 & 10 \\
\hline $\begin{array}{l}\text { PPN No snow } \\
\text { No snow }\end{array}$ & $5472 \times 3648$ & 36 & 12 \\
\hline \begin{tabular}{l} 
PPN I test \\
\hline $\begin{array}{l}\text { PPN snow } \\
- \text { II test }\end{array}$
\end{tabular} & $4000 \times 2250$ & 34 & 10 \\
\hline
\end{tabular}

Table 5. Images resolution and measured target for the model georeferencing and for accuracy estimation.

The outputs of these operations are dense point clouds that describe both the ground and the objects above it (i.e. vegetation, buildings, ski lifts etc.). In order to perform analyses regarding the ground behaviour, it was essential to filter this information and obtain a DTM. AMP was then used to classify the ground points with an automatic approach. The automatic classification procedure provides for a first approximation of the terrain model from the lowest points detected. Next, each other point is added to the class "terrain" only if its position is within a certain distance from the terrain model and if the angle between the terrain model and the connecting line of this new point to a point in the class "terrain" is lower than a certain angle value, set by the user. This operation was repeated for all the datasets and, finally, all the points classified as "terrain" can were used to generate the DTMs. For this research study, in addition to the DTMs, also the Digital Surface Models (DSMs) and orthophotos were extracted.

The DTMs obtained from the photogrammetric process served as input data for the estimation of snow depth. The analysis was focused exclusively on the extension of the ski slopes, considering an offset of about $1 \mathrm{~m}$ with respect to the borders. For the estimation of the snow depth the height of the snow-free terrain, stored in the raster datasets, was subtracted to the height of the snowpack in recorded the other DTMs, using the Raster Math toolbox, of the ArcMap software. The output are new raster products, containing in each cell the value of the snow depth.

\subsection{Wallis filter}

To benefit from the advantages deriving from the use of photogrammetry, the quality of the images acquired and used in the photogrammetric process plays a role of fundamental importance for the correct success of the reconstruction of the three-dimensional model in all its aspects (Pierrot-Deseilligny et al., 2011). Often some problems due to jpeg artifacts, motion blur, sensor noise, etc... can negatively affect the success of the $3 \mathrm{D}$ model realization. For this reason, images were pre-processed before starting the digital photogrammetry workflow.

One of the main problems encountered in the images acquired in the field concerns the presence or not of shadows on the snowpack, mainly due to the rapid variation of the weather conditions in the mountain environment. A second problem encountered during the acquisition phase concerns the nature of the snowpack characterized by a uniform texture, mainly in the areas of the track where skiers have not passed and consequently there is no presence of traces on the ground. This prevents the SFM algorithms from identifying homologous points in the images and correlating them. The worst case occurred in conditions of uniform light (no shadows) and snow beaten by the snow cat. In this case, a white balance was tested in the set of images with the aim of obtaining radiometrically-calibrated images ensuring as much as possible a consistency of color on the entire detected surface, however obtaining a result that is not sufficient to solve the problem encountered (Figure 7).

In a second phase, the Wallis filter was tested (Wallis, 1976), particularly suitable for low-texture surfaces such as the snowpack, trying to improve contrast levels and flatten the different exposures to obtain a homogeneous brightness in all images. The Wallis filter was tested because, having shaded and non-shaded areas in the same image, it is necessary to use an adaptive algorithm that operates on small areas instead of the whole image, adjusting the single pixel by comparing it with the adjacent ones. Wallis uses two parameters to control the enhancement's amount, the contrast expansion factor A and the brightness forcing factor B, and returns an image containing more details both in the high and low contrast areas, thus ensuring an improvement of the image in its totality. 

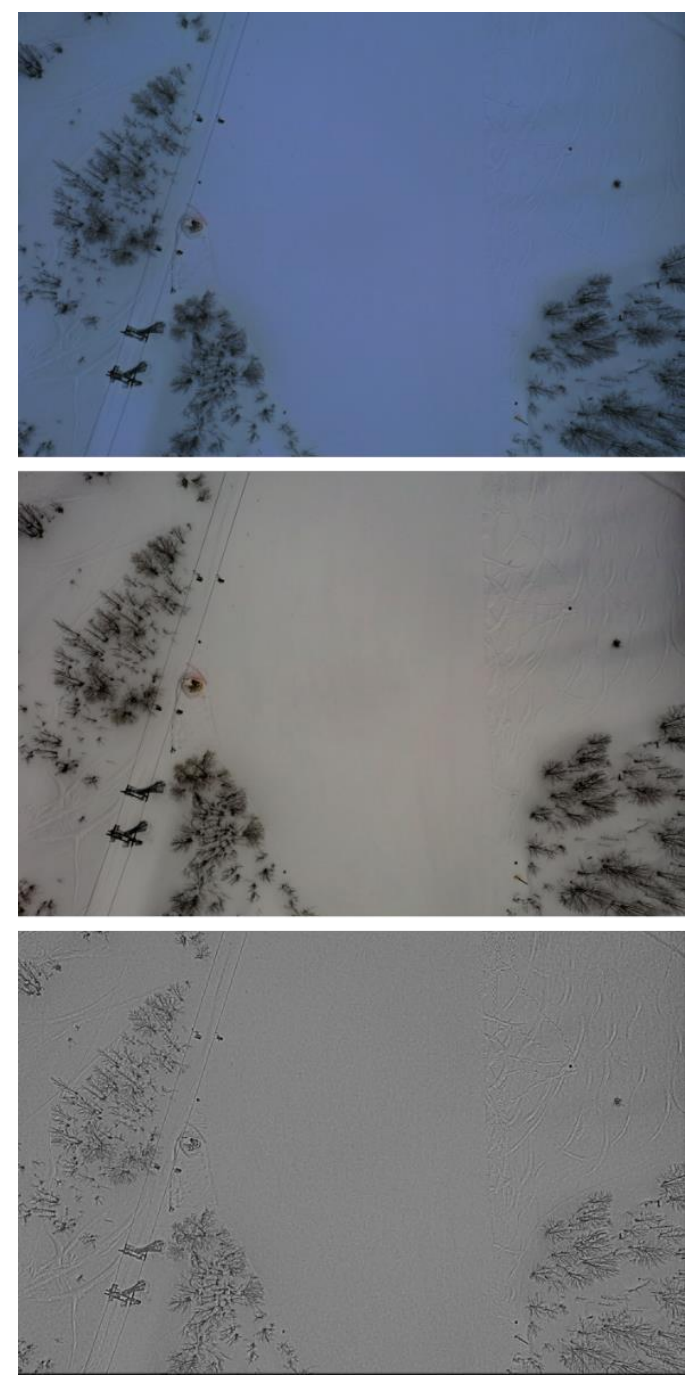

Figure 7. Example of image editing: the original image acquired by Mavic 2 Pro (upward), the with balance application (in centre) and the use of the Wllis filter (below).

Firstly Wallis divides the input image into neighbouring square blocks with a user-defined size in order to calculate local statistics. After that mean (M) and standard deviation (S) of the unfiltered image are calculated for each individual block based on the grey values of the pixels and the resulting value is assigned to the central cell of each block. The mean and standard deviation values of other cells in the block are calculated from this central cell by bilinear interpolation. In this way, each individual pixel gets its own initial local mean and standard deviation based on surrounding pixel values. The user-defined mean and standard deviation values are then used to adjust the brightness and the contrast of the input cells. The resulting Wallis filtered image is thus a weighted combination of the original and user-defined mean and standard deviation of the image (Gaiani et al., 2016). In this case, the filter was tested by varying the parameters several times but not finding an acceptable improvement in the images useful for solving the problems highlighted above (Figure $6)$.

\section{RESULTS AND DISCUSSION}

\subsection{Results of the photogrammetric processing}

The six datasets were then processed using AMP, configured according to the settings described in Section 4. After the orientation phase (Bundle Block Adjustment), dense point clouds were computed by the various implemented algorithms and allowed to obtain suitable products for large scale purposes (Table 6).

\begin{tabular}{|c|c|c|c|c|}
\hline \multirow{2}{*}{ Dataset } & \multicolumn{3}{|c|}{$\begin{array}{c}\text { Residuals } \\
\text { on CPs [mm] }\end{array}$} & \multirow{2}{*}{$\begin{array}{c}\text { N. points of } \\
\text { dense point } \\
\text { cloud } \\
\text { [Mpoints] }\end{array}$} \\
\hline & $\Delta \mathrm{X}$ & $\Delta \mathrm{Y}$ & $\Delta \mathrm{Z}$ & \\
\hline $\begin{array}{l}\text { ALP } \\
\text { No snow }\end{array}$ & 14 & 18 & 27 & 350 \\
\hline $\begin{array}{l}\text { ALP snow } \\
\text { - I test }\end{array}$ & 11 & 10 & 13 & 77 \\
\hline $\begin{array}{l}\text { ALP snow } \\
\text { - II test }\end{array}$ & 23 & 19 & 50 & 85 \\
\hline $\begin{array}{l}\text { PPN } \\
\text { No snow }\end{array}$ & 27 & 19 & 43 & 103 \\
\hline $\begin{array}{l}\text { PPN snow } \\
\text { - I test }\end{array}$ & 15 & 29 & 19 & 119 \\
\hline $\begin{array}{l}\text { PPN snow } \\
\text { - II test }\end{array}$ & 11 & 22 & 42 & 93 \\
\hline
\end{tabular}

Table 6. Residuals on CPs on the resulting dense point clouds.

According to the acquired data, the obtained point clouds offer complete 3D models of the ski tracks. Generally, the noise level of the dense point clouds is rather limited, only some areas, beyond the borders of the Armand slope, are disturbed by the presence of vegetation. The only exception is the first test conducted on the Armand track in the presence of snow. During the survey phase, due to the fast variability of the weather conditions, the images of the lower part of the track were acquired in uniform light conditions. The absence of shadows and the uniformity of the snowy coat beaten by the snow cat, prevented the SFM algorithms from Identifying homologous points. In this circumstance, although residues on GCPs and CPs were acceptable, the dense cloud was visibly very noisy in this area and this would lead to a wrong estimation of the thickness. Several tests on the images were conducted: in addition to the white balance, the Wallis filter was applied, varying from time to time the various parameters (i.e. window size, contrast, etc.). The results obtained were, however, not satisfactory and it was decided to process only the images related to the upper part of the track, acquired in the presence of sunlight.

The final steps involved the generation of the DTMs, DSMs and orthophotos in the coordinates system WGS84 - UTM 32N. The resolutions of these products was chosen according to the accuracies of the obtained 3D models, of about 3-4 cm.

\subsection{Snow depth estimation}

To estimate the depth of the snow, the difference in altitude between the DTM of the snow-free terrain and the DTM of the snow altitude has been calculated (Figure 8). 


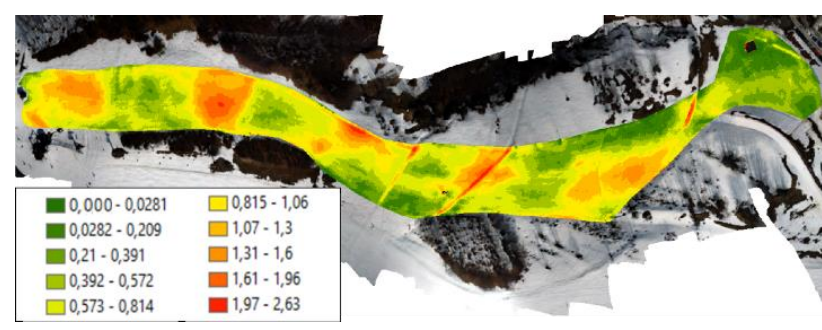

Figure 8. Example of snow depth estimation, as difference between the DTM of snow level of the Armand slope, realized with data collected during the second survey campaign, and the DTM representing the "zero" height of the ground.

The Table 7 shoes the mean, maximum and minimum snow depth estimated on the two study areas.

\begin{tabular}{|c|c|c|c|}
\hline $\begin{array}{l}\text { Dataset } \\
\text { (snow) }\end{array}$ & $\begin{array}{l}\text { Avg. depth } \\
{[\mathrm{m}]}\end{array}$ & $\begin{array}{c}\text { Max. depth } \\
{[\mathrm{m}]}\end{array}$ & $\begin{array}{l}\text { Min. depth } \\
{[\mathrm{m}]}\end{array}$ \\
\hline $\begin{array}{l}\text { ALP snow } \\
\text { - I test }\end{array}$ & 1.08 & 2.6 & 0.48 \\
\hline $\begin{array}{l}\text { ALP snow } \\
\text { - II test }\end{array}$ & 0.67 & 2.63 & 0.22 \\
\hline $\begin{array}{l}\text { PPN snow } \\
\text { - I test }\end{array}$ & 0.92 & 2.50 & 0.04 \\
\hline $\begin{array}{l}\text { PPN snow } \\
\text { - II test }\end{array}$ & 0.73 & 2.43 & 0.07 \\
\hline
\end{tabular}

Table 7. Snow depth values.

The estimated snow thickness values are consistent with what the ski resort managers expected. As assumed, there are variations along the ski slopes, mainly due to the presence of depressions and pedestrian paths on the original terrain. The differences between the thickness calculated as a result of the first tests, carried out at the end of January, and the estimated thickness after the second test, carried out at the beginning of March, for each of the two stations, shows how, the increase in the typical temperatures of the late season, caused a slight decrease in snow cover. The effect of the melting snow is appreciable at the bottom of the slopes, where the snow is particularly thin, also because of the massive passage of people.

\subsection{Snow groomer GNSS data analysis}

The evaluation of the quality of positioning has been conducted considering the mean, maximum and minimum standard deviation, computed in North, East and Up components.

The solutions obtained with the Tersus BX-306 showed that mean standard deviation values are lower than $1 \mathrm{~cm}$ for horizontal components, whereas around $1 \mathrm{~cm}$ for vertical component.

In order to obtain the highest accuracy in the RTK positioning, is fundamental to fix the carrier phase ambiguities to integer numbers. We, therefore, considered a statistical method also known as ratio test (Cina et al., 2014). High values of ratio (>3) indicates that the chosen solution is at least 3 times better than the next most likely solution and the solution can be defined as "fixed"; otherwise, if the value of ratio is between 0 and 3 then the solution will be defined as "float".

During the RTK positioning test the percentage of Float solution was equal to $22 \%$, while the carrier phase ambiguities were fixed to integer numbers for the $78 \%$ of the solutions (Figure 9).

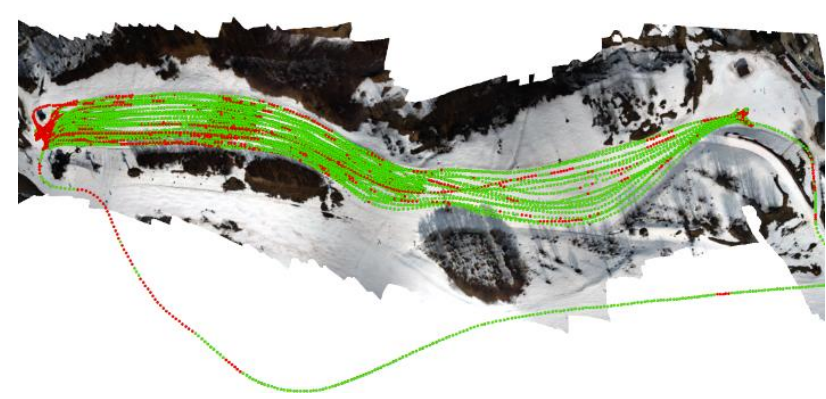

Figure 9. The snow groom positioning: in red are represented the Float solutions and, in green, the Fixed solutions.

Knowing the leverage arm between the GNSS antenna and the central point at the bottom of the blade, and the attitude of the vehicle, estimated considering the position previously measured, it is possible to calculate the snow height, in a certain point at a specific time. The snow thickness can be estimated as difference between the height of the bottom of the blade and the height of the reference terrain (Figure 10). This represent the first step of a research work aiming at estimate the snow depth, in real-time, during the snow modelling operations.

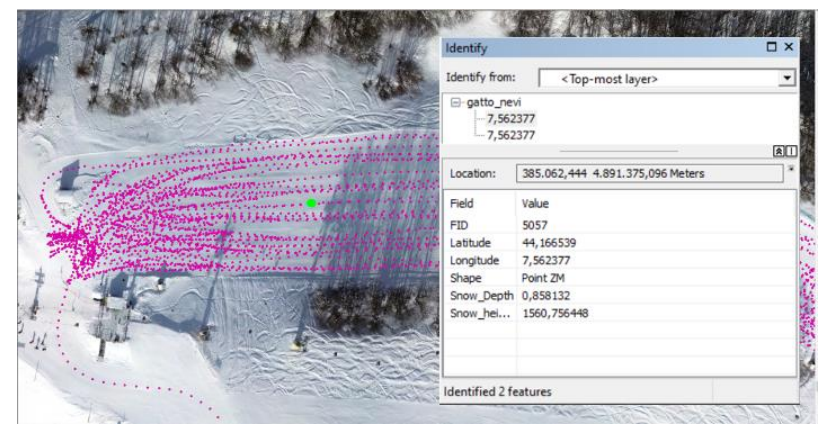

Figure 10. Visualization of the snow altitude on a Geographical Information System (GIS), estimated as the difference in altitude between the lowest point of the blade and the reference terrain.

\section{CONCLUSIONS}

One of the main energy-consuming elements of ski resorts concerns the production of artificial snow, a requirement which is also growing due to climate change and which creates a strong environmental pressure at local level, with the need to create special tanks at high altitude or water abstractions during the winter, with strong gas emissions related to the production of electricity that feeds the fans for snow production.

The research work described here fits into the activities of the Alpimed-INNOV project, which, among the various objectives, has to optimize the use of water and energy efficiency for production of the artificial snow on the ski slopes. In this regard, among the various technological solutions available today, it was decided to evaluate the performances of UAV systems for the estimation of snow thickness along the ski slopes and to monitor the movements of snow cats with GNSS receivers at low cost, for the calculation and optimisation of fuel use. The main objective of the study was to provide low-cost and easily available solutions to the managers of the ski resorts.

The results obtained confirm that, starting from aerial images, it is possible, through SfM algorithms, to model the ski slopes and estimate, compared to a reference model, the thickness of the snow cover. In particular, the resulting accuracy is sufficient to highlight the irregularities of the surface of the track, to estimate the amount of artificial snow to be produced and to identify the areas on which to intervene to standardize the surface. However 
it has been observed how the products obtained from images acquired in presence of snow, depend strongly on the light conditions of the environment and the presence, or not, of irregularities of the snow cover. In the future, it will be necessary to evaluate the use of different sensors, such as hyperspectral cameras, to ensure that the light variation does not preclude the possibility of modelling the terrain.

This work has also showed that, double-frequency mass-market GNSS sensors could be considered as valid alternative to more expensive receivers, for the survey of the snow groomers routes in real-time. Future works will be focused on the study of a lowcost system integrated with GNSS receiver and inertial platform for real-time estimation of snow thickness, to be used to maneuver the snow cat.

\section{ACKNOWLEDGEMENTS}

The activities described were carried out within the Project PITER Alpimed - INNOV, part of the cross-border cooperation programme Alcotra Italy-France Interreg V A 2014-2020, as the Department of Environment, Land and Infrastructure Engineering (DIATI) of Politecnico di Torino is an implementing entity of the Project.

\section{REFERENCES}

Aicardi, I., Chiabrando, F., Grasso, N., Lingua, A. M., Noardo, F., \& Spanò, A. (2016a). UAV photogrammetry with oblique images: first analysis on data acquisition and processing. International Archives of the Photogrammetry, Remote Sensing \& Spatial Information Sciences, 41.

Aicardi, I., Nex, F., Gerke, M., \& Lingua, A. M. (2016b). An image-based approach for the co-registration of multi-temporal UAV image datasets. Remote sensing, 8(9), 779.

Avanzi, F., Bianchi A., Cina A., De Michele C., Maschio P., Pagliari D., Passoni D., Pinto L., Piras M., Rossi L., Centimetric Accuracy in Snow Depth Using Unmanned Aerial System Photogrammetry and a MultiStation. Remote Sens. 2018, 10, 765, 2018; doi:10.3390/rs10050765.

Balletti, C., Guerra, F., Tsioukas, V., \& Vernier, P. (2014). Calibration of action cameras for photogrammetric purposes. Sensors, 14(9), 17471-17490.

Bühler, Y., Adams, M.S., Bösch, R., Stoffel, A., Mapping snow depth in alpine terrain with unmanned aerial systems (UASs): potential and limitations. The Cryosphere, 10, 1075-1088, 2016; doi:10.5194/tc-10-1075-2016.

Cina, A., Dabove, P., Manzino, A. M., \& Piras, M. (2014, May). Augmented positioning with CORSs network services using GNSS mass-market receivers. In 2014 IEEE/ION Position, Location and Navigation Symposium-PLANS 2014 (pp. 359366). IEEE.

Dawson, J., and Scott D. "Managing for climate change in the alpine ski sector." Tourism Management 35, 2013: 244-254.

Gaiani, M., Remondino, F., Apollonio, F. I., Ballabeni, A., An Advanced Pre-Processing Pipeline to Improve Automated Photogrammetric Reconstructions of Architectural Scenes. Remote Sens. 2016, 8(3), 178; doi.org/10.3390/rs8030178.

Goetz, J., Brenning, A., Quantifying Uncertainties in Snow Depth Mapping From Structure From Motion Photogrammetry in an Alpine Area. Water Resources Research. Advancing Earth and Space Science, 2019; doi.org/10.1029/2019WR025251.

He, H.; Li, J.; Yang, Y.; Xu, J.; Guo, H.; Wang, A. Performance assessment of single- and dual-frequency BeiDou/GPS singleepoch kinematic positioning. GPS Solut. 2014, 18, 393-403.

Lingua, A., Noardo, F., Spanò, A., Sanna, S., \& Matrone, F. (2017). 3D model generation using oblique images acquired by UAV. International Archives of the Photogrammetry, Remote Sensing \& Spatial Information Sciences, 42.

Marino, B. G., Masiero, A., Chiabrando, F., Lingua, A. M., Fissore, F., Błaszczak-Bak, W., \& Vettore, A. (2019). Data optimization for $3 \mathrm{~d}$ modeling and analysis of a fortress architecture. International Archives of the Photogrammetry, Remote Sensing \& Spatial Information Sciences.

Masiero, A., Fissore, F., Pirotti, F., Guarnieri, A., \& Vettore, A. (2016). Toward the use of smartphones for mobile mapping. Geo-spatial Information Science, 19(3), 210-221.

Pierrot-Deseilligny, M., De Luca, L., Remondino, F.. Automated image-based procedures for accurate artifacts 3D modeling and orthoimage generation. Geoinformatics FCE CTU Journal, Vol. 6, pp. 291-299, 2011.

Rixen, C., Teich, M., Lardelli, C., Gallati, D., Pohl, M., Pütz, M., \& Bebi, P. (2011). Winter tourism and climate change in the Alps: an assessment of resource consumption, snow reliability, and future snowmaking potential. Mountain Research and Development, 31(3), 229-236.

Scott, D., Steiger, R., Rutty, M., Pons, M., \& Johnson, P. (2019). The differential futures of ski tourism in Ontario (Canada) under climate change: The limits of snowmaking adaptation. Current Issues in Tourism, 22(11), 1327-1342.

Steiger, R., Scott, D., Abegg, B., Pons, M., \& Aall, C. (2019). A critical review of climate change risk for ski tourism. Current Issues in Tourism, 22(11), 1343-1379.

Turner, D.; Lucieer, A.; Watson, C. An Automated Technique for Generating Georectified Mosaics from Ultra-High Resolution Unmanned Aerial Vehicle (UAV) Imagery, Based on Structure from Motion (SfM) Point Clouds. Remote Sens. 2012, 4, 13921410 .

Wallis R., An approach to the space variant restoration and enhancement of images. Proceedings of Symp. Current Mathematical Problems in Image Science, Monterey, Naval Postgraduate School, pp. 329-340, 1976. 